\title{
Estratigrafia do Grupo Bambuí na Serra da Saudade e geologia do depósito fosfático de Cedro do Abaeté, Minas Gerais
}

\author{
Otávio Nunes Borges Lima', Alexandre Uhlein ${ }^{2} \&$ Walter de Britto $^{3}$
}

\begin{abstract}
Resumo Este trabalho descreve o Grupo Bambuí na Serra da Saudade, caracterizando depósitos de fosfato sedimentar. Apresentam-se descrições das unidades litoestratigráficas, com auxílio de coluna estratigráfica, mapa e seções geológicas. As litofácies da Formação Serra da Saudade incluem: (1) ritmito pelito-arenoso; (2) arenito fino com estratificação cruzada hummocky; (3) ritmito areno-pelítico verde (verdete) glauconítico; (4) ritmito fosfático; (5) carbonatos retrabalhados (calcirudito e calcarenito). Os sedimentos da Fm. Serra da Saudade foram depositados em uma plataforma relativamente profunda, periodicamente influenciada por ondas de tempestades, mostram padrão de granocrescência ascendente, são imaturos e depositados numa bacia sob a influência de processos colisionais. Os ritmitos fosfáticos (fosfoarenitos) estão situados próximos à cidade de Cedro do Abaeté-MG. Os ritmitos consistem de intraclastos fosfáticos em uma matriz microcristalina (micrítica) formada por grãos de fluorapatita, em adição a outros minerais detríticos como o quartzo, K-feldspato, plagioclásio, micas e clorita. A fosfatização é uma fase sindiagenética, mas com importante desenvolvimento de wavelita por alteração supergênica.
\end{abstract}

Palavras-chave: Grupo Bambuí, Formação Serra da Saudade, sedimentologia, glauconita, fosfato sedimentar.

\begin{abstract}
Stratigraphy of the Bambui Group in the Serra da Saudade, Minas Gerais, and Geology of the Phosphate Deposits. This work focalizes the Bambuí Group in the Serra da Saudade, including lithostratigraphical units description, geological map, and cross sections drawing. The lithofacies of the Serra da Saudade Formation were described: (1) pelitic-psamitic rhythmites; (2) sandstone with hummocky cross estratification; (3) green glauconitic rhythmite; (4) phosphatic rhythmite; (5) reworked carbonates (calcirudites and calcarenites). The pelitic-sandy sediments of Serra da Saudade Formation were deposited on a platform lying at a mean water depth periodically influenced by storm currents. The Serra da Saudade Formation terrigenous rocks show coarsening upward sequence, are immature sediments and were accumulated in a basin under the influence of collisional processes. The phosphatic rhythmite (phosphoarenite) is situated near Cedro do Abaeté city. It consists of phosphate intraclasts in a microcrystalline grained matrix (micrite), rich in fluorapatite, and addition to detrital quartz, feldspar, muscovite and other minerals.The phosphatization is a syn-diagenetic phase, but with important development of the wavelite by the supergene alteration.
\end{abstract}

Keywords: Bambuí Group, Serra da Saudade Formation, sedimentology, phosphate.

INTRODUÇÃo A Serra da Saudade constitui o domínio elevado de cristas interplanálticas que acompanham os interflúvios das bacias hidrográficas do alto rio São Francisco e do rio Indaiá, no centro-oeste mineiro, que avança em direção norte até o lago da represa de Três Marias (Fig. 1). As principais cidades da região são Abaeté, Paineiras, Biquinhas e Cedro do Abaeté. O rio Indaiá é o seu principal eixo de drenagem.

Na literatura geológica, a Serra da Saudade ganhou notoriedade por ser a seção tipo da formação homônima, unidade estratigráfica definida originalmente por Costa \& Branco (1961), que a colocaram no topo do Grupo Bambuí. O posicionamento estratigráfico da Formação Serra da Saudade foi revisto por Dardenne (1978), que a colocou sotoposta à Formação Três Marias. Desde então, essa proposta estratigráfica foi man- tida nos sucessivos trabalhos realizados, como no Projeto São Francisco (COMIG/CPRM 2002).

A Formação Serra da Saudade possui rochas areno-pelíticas e pelíticas de cor verde, tradicionalmente conhecidas como verdetes, e depósitos areno-fosfáticos encontrados, principalmente, entre as cidades de Cedro do Abaeté-MG e Quartel São João-MG, no alto da Serra da Saudade. Os depósitos de fosfatos sedimentares foram reconhecidos e mapeados anteriormente pelo Projeto Cedro do Abaeté (Chaves et al. 1971). Posteriormente foram mencionados por Dardenne et al. (1986), em artigo sobre fosfatos proterozóicos de origem sedimentar.

O objetivo deste trabalho é contribuir com dados estratigráficos sobre o Grupo Bambuí na região da Serra da Saudade e apresentar dados petrográficos e se-

1 - PETROBRÁS UM-ES/ATP-JUB, Vitória (ES), Brasil. E-mail: otaviolima@petrobras.com.br

2 - Departamento de Geologia, Instituto de Geociências, Universidade Federal de Minas Gerais, Belo Horizonte (MG), Brasil. E-mail:

uhlein@netuno.lcc.ufmg.br

3 - Centro de Desenvolvimento de Tecnologia Nuclear-CNEN, Belo Horizonte (MG), Brasil. E-mail: britow@cdtn.br 


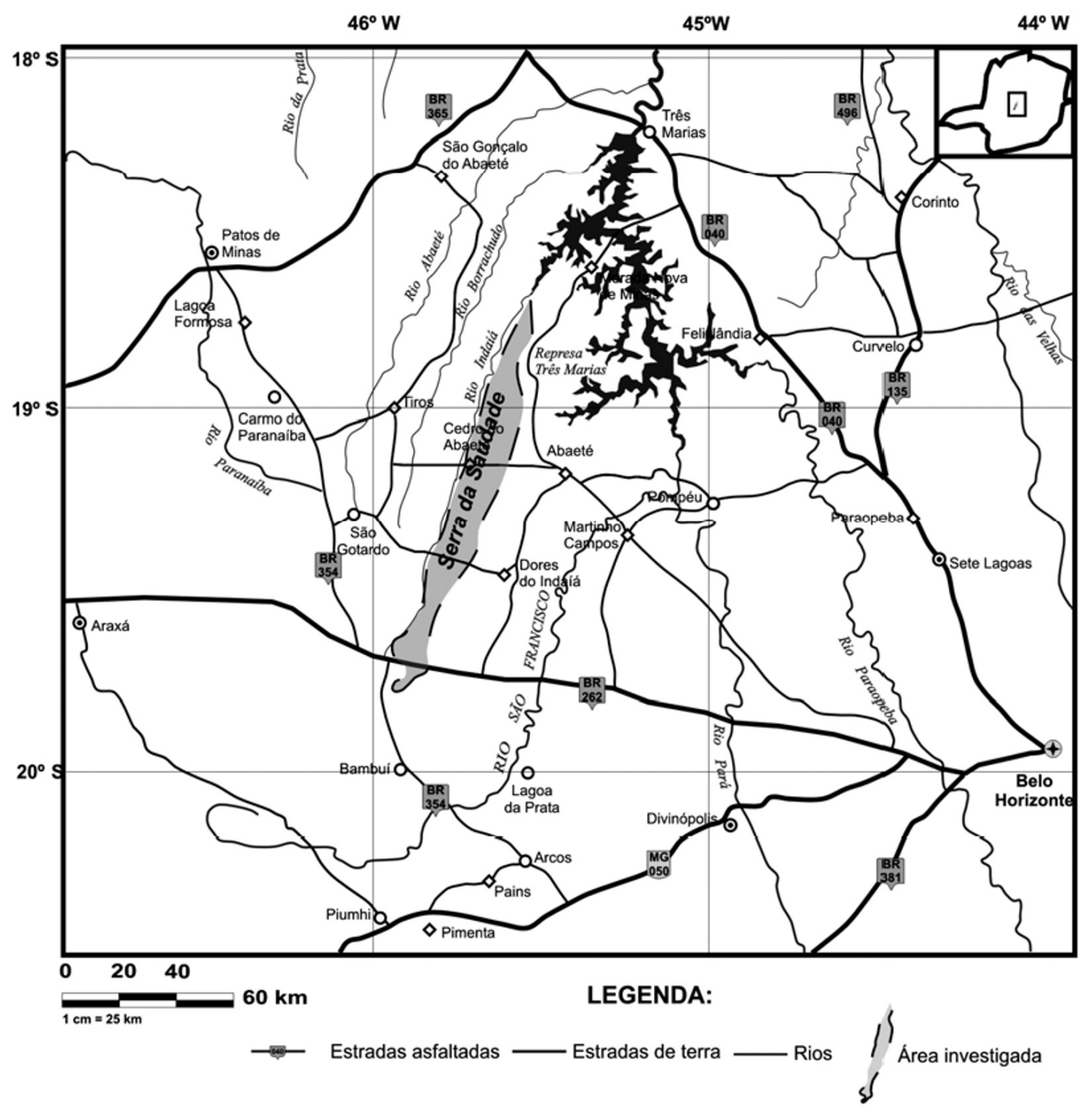

Figura 1 - Mapa de localização da Serra da Saudade em Minas Gerais, com as principais vias de acesso.

dimentológicos sobre o depósito fosfático, procurando delinear sua evolução geológica. A região é de difícil acesso e carente de dados científicos relevantes.

ESTRATIGRAFIA E SEDIMENTOLOGIA DO GRUPO BAMBUÍ NA SERRA DA SAUDADE O Grupo Bambuí constitui-se numa unidade estratigráfica formada por litofácies siliciclásticas e carbonáticas (químicas, bioquímicas e de retrabalhamento), depositadas sobre uma plataforma marinha epicontinental, no final do Neoproterozóico (700 - $600 \mathrm{Ma})$. A distribuição geográfica do Grupo Bambuí, e correlatos, é ampla e contínua ao longo de uma expressiva faixa do Brasil central. Ocorre ao longo de vastas áreas dos estados de Minas Gerais, Bahia, Goiás e parte do Distrito Federal.

A estratigrafia clássica, e mais usual, do Grupo Bambuí foi definida por Costa \& Branco (1961) e por Dardenne (1978, 1981). Segundo Dardenne (1978) o Grupo Bambuí é constituído por seis formações, a sa- ber: Fm. Jequitaí, Fm. Sete Lagoas, Fm. Serra de Santa Helena, Fm. Lagoa do Jacaré, Fm. Serra da Saudade e Fm. Três Marias.

A unidade basal, Fm. Jequitaí, é glaciogênica e constituída por diamictitos e, subordinadamente, arenitos e pelitos. A Fm. Sete Lagoas representa uma unidade carbonática, formada por calcários laminados, calcários e dolomitos estromatolíticos, doloarenitos e brechas dolomíticas, depositados em ambientes de intermaré, inframaré e plataforma carbonática (Nobre-Lopes 1995, Lima 1997). A Fm. Serra de Santa Helena representa uma espessa unidade dominada por siliciclásticos finos, principalmente siltitos, folhelhos e arenitos muito finos e impuros, depositados em plataforma dominada pela ação de ondas normais e de tempestades (Guimarães 1997). A Fm. Lagoa do Jacaré é caracterizada pela associação de depósitos carbonáticos de retrabalhamento, principalmente calcarenitos oolíticos a pisolíticos, calciruditos e doloruditos, intercalados com níveis de es- 
pessura variável de siltitos e, raras, bioconstruções carbonáticas. A Fm. Serra da Saudade, de ocorrência mais restrita, e também dominantemente siliciclástica é formada por ritmitos silto-arenosos, localmente fosfáticos, siltitos, arenitos grauvaquianos e subarcosianos e, mais raramente, por pelitos verdes conhecidos na literatura geológica como verdetes (Lima 2005). A unidade superior, Fm. Três Marias é dominada por arenitos arcoseanos médios a finos, mostrando truncamentos de baixo ângulo e estratificação cruzada hummocky, intercalados em silititos e ritmitos, depositados em plataforma siliciclástica dominada pela ação de ondas de tempestade (Chiavegatto 1992).

Por meio do apoio dos mapas do Projeto São Francisco, análise de imagens Landsat, e observações de campo, efetuadas pelos autores, foi possível confeccionar o mapa geológico (Fig. 2) da região da Serra da Saudade e seu prolongamento norte, a Serra do Palmital. No mapa são individualizadas as Formações Serra de Santa Helena (predominando a leste), Serra da Saudade (ocorrendo na Serra homônima, porção oeste do mapa), e, para norte, a Formação Três Marias. Rochas do Cretáceo, constituídas pelos Grupos Areado (arenitos) e Mata da Corda (vulcânicas básicas alcalinas) ocorrem em discordância sobre os sedimentos proterozóicos. Coberturas inconsolidadas são freqüentes, principalmente na região norte de Abaeté. Duas seções geológicas são apresentadas na figura 3. A primeira, mais ao sul (A-B), passa pela cidade de Cedro do Abaeté, mostra a Formação Serra da Saudade com maior espessura ( $200 \mathrm{~m})$ e a importância dos dobramentos de eixos norte-sul. A segunda (C-D) mostra a estrutura da Serra do Palmital, menor espessura da Form. Serra da Saudade e a importância da cobertura cretácea.

Dados estratigráficos sobre a região da Serra da Saudade são mostrados na figura 4. Identificaramse cinco litofácies na Formação Serra de Santa Helena, cinco na Formação Serra da Saudade e duas na Formação Três Marias.

Formação Serra de Santa Helena A Formação Serra de Santa Helena representa a unidade litoestratigráfica de maior expressão, correspondendo a base do Grupo Bambuí na área investigada. A espessura deste conjunto é superior a $250 \mathrm{~m}$. Constitui-se da intercalação de ritmitos pelito-arenosos e camadas centimétricas e, às vezes, decimétricas, de siltitos argilosos e ocorrência esparsa de lentes de carbonatos detríticos. Cinco litofácies foram reconhecidas na Fm. Serra de Santa Helena: (1) Ritmito; (2) Siltito argiloso maciço; (3) Arenito muito fino com laminação cruzada; (4) Carbonatos; (5) Siltito com hummocky.

Os ritmitos, que representam a litofácies mais abundante, são areno-silto-argilosos, com leitos de arenito fino e siltito, esse último com lâminas argilosas. Estratificação e laminação plana predo minam, mas laminações cruzadas (climbing ripples) e estratificação cruzada por ondas (hummocky) podem ocorrer (Uhlein et al. 2004, Lima 2005).

Petrograficamente, ao microscópio, esses ritmi- tos mostram 40 a $50 \%$ de quartzo, 30 a $40 \%$ de feldspatos (plagioclásio predomina) e 10 a $20 \%$ de filossilicatos, na forma de micas detríticas. Acessórios são turmalina, epidotos, zircão, opacos e fragmentos líticos.

Os carbonatos detríticos foram encontrados em Abaeté e na Serra do Tigre (Fig. 2). Em Abaeté ocorrem calcarenitos, brechas e calcilutitos. Na Serra do Tigre observou-se bioconstruções estromatolíticas com intercalações de doloruditos. Podem representar a Formação Lagoa do Jacaré na área, entretanto, a unidade não foi individualizada no mapa geológico.

Formação Serra da Saudade As litofácies da Formação Serra da Saudade ocorrem, principalmente, na parte sul da área investigada, próximo da cidade de $\mathrm{Ce}$ dro do Abaeté, onde atingem uma espessura de cerca de 200 metros. Para o norte (Serra do Palmital), a espessura diminui. Cinco litofácies foram reconhecidas na Fm. Serra da Saudade: (1) Ritmito pelito-arenoso; (2) Carbonatos retrabalhados; (3) Ritmito areno-pelítico verde (verdete); (4) Arenito fino com hummocky; (5) Ritmito fosfático.

Os ritmitos pelito-arenosos predominam na base, mostram leitos psamíticos com alguns centímetros de espessura, de granulometria média-fina, que se alternam com leitos pelíticos (silto-argilosos). Os carbonatos retrabalhados ocorrem nas cercanias de Cedro do Abaeté e são lenticulares, na forma de calcarenitos e calciruditos, intercalados com os verdetes. Os arenitos finos com hummocky predominam para o topo, mostram superfícies de truncamento de baixo ângulo e comprimentos de onda entre 1 e 2 metros. Os arenitos são imaturos texturalmente e mineralógicamente, com granulometria variando de areia média a silte e grãos angulosos a sub-angulosos. Petrograficamente são constituídos por quartzo (50-40\%), micas, cloritas e argilo-minerais (30\%), feldspatos (15 a $10 \%$ ) e acessórios como zircão, rutilo e opacos.

Os ritmitos areno-pelíticos verdes (Figs. 4 e 5) são formados pela sucessão de camadas de 0,5 a $30 \mathrm{~cm}$, predominando de 2 a $10 \mathrm{~cm}$, que afloram nas porções elevadas da Serra da Saudade, nos arredores de Cedro do Abaeté, com espessura aproximada de até 80 metros. São rochas bem estratificadas, com base arenosa e topo silto-argiloso, com predomínio de camadas planas ou onduladas, com base plana e topo exibindo convexidades e, internamente, truncamentos de baixo ângulo, considerados como estratificações cruzadas por ondas (hummockys) e interpretados como fácies de tempestitos (Uhlein et al. 2004, ponto 18, pg. 25). Os ritmitos areno-pelíticos verdes (verdetes) podem exibir internamente ciclos de granodecrescência ascendente (Fig. 5), com granulometria variando, na base, de areia fina a síltica até silto-argilosa no topo, mostrando cor verde. A tonalidade verde também pode variar de mais clara na base (areno-siltosa) a mais escura no topo, principalmente quando coincide com lâminas argilosas. Assim, à medida que a granulometria decresce, a cor verde, torna-se mais intensa, mostrando que o mineral cromóforo está concentrado nas frações argilosas. Os verdetes 


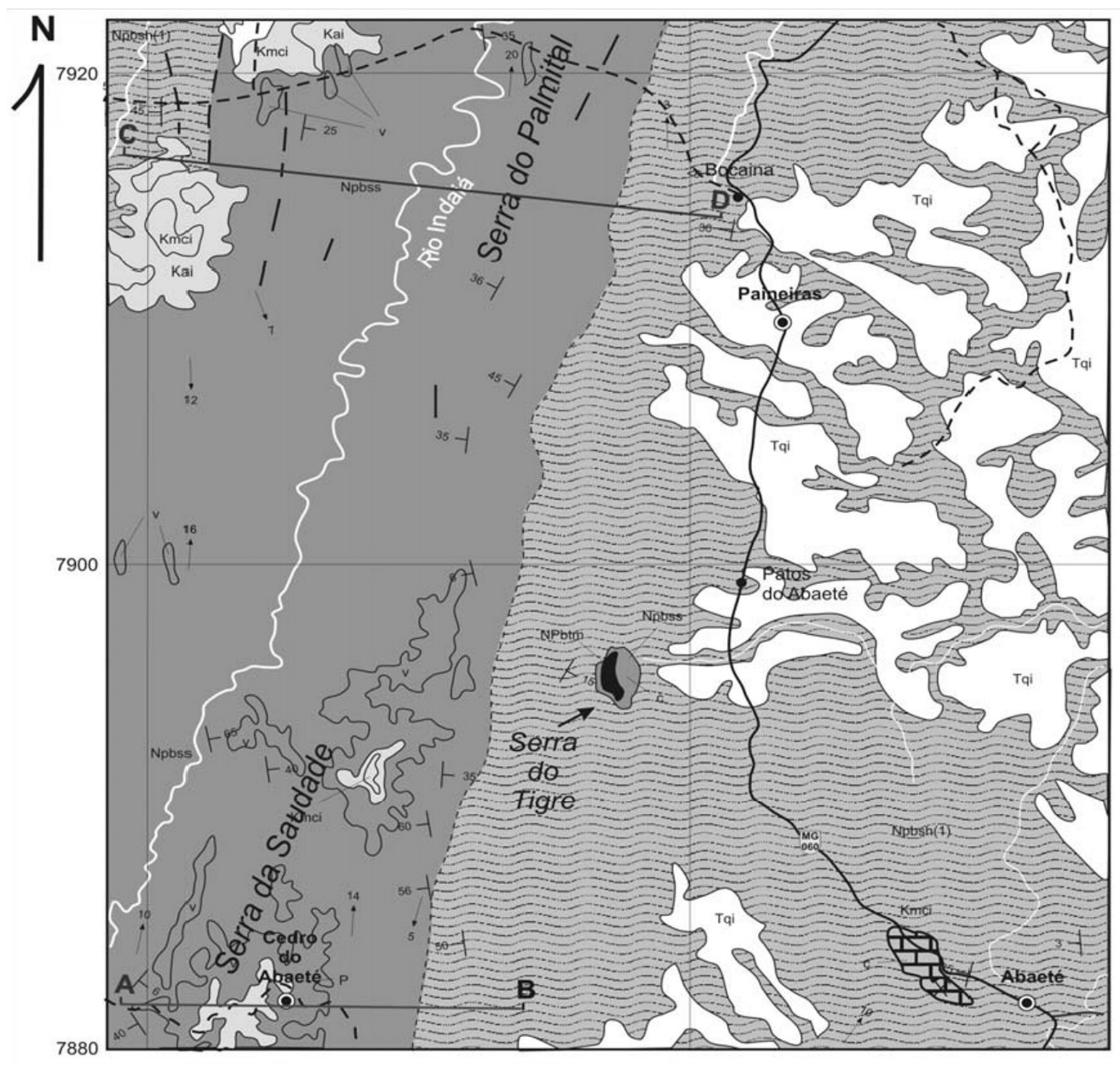

\section{CENOZÓICO}

INDIVISO

Ta Sedimentos inconsolidados de natureza MESOZÓıCO - Cretáceo

Kund Gr. Mata da Corda (Kmcl) - rochas vulcânica e vulcanoclásticas: Gr. Areado (Kmci) arenitos e localmente, conglomerados polimiticos.

\section{NEOPROTEROZOICO}

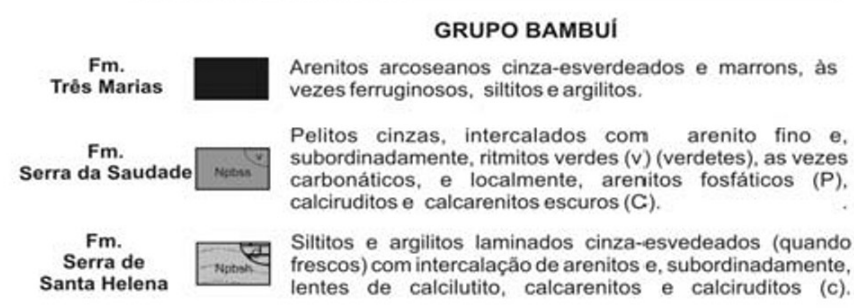

\section{CONVENÇÕES CARTOGRÁFICAS}

SIMBOLOS GEOLÓGICOS

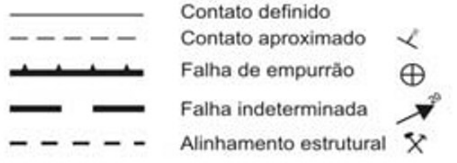
Acamamento com mergulho
Acamamento horizontal
Lineaçăo b com caimento medido
Mina em atividade

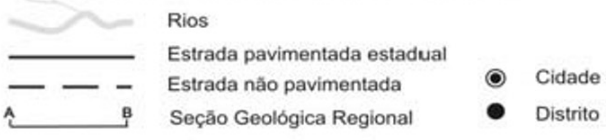

ESCALA

Figura 2 - Mapa geológico da Serra da Saudade. Compilação dos mapas 1: 250 000, Folhas Três Marias e Bom Despacho, do Projeto São Francisco (COMIG/CPRM 2002) e dados adicionais, obtidos pelos autores em trabalhos de campo. Ver localização das seções geológicas $A-B$ e $C$-D, referentes a figura 3 . 

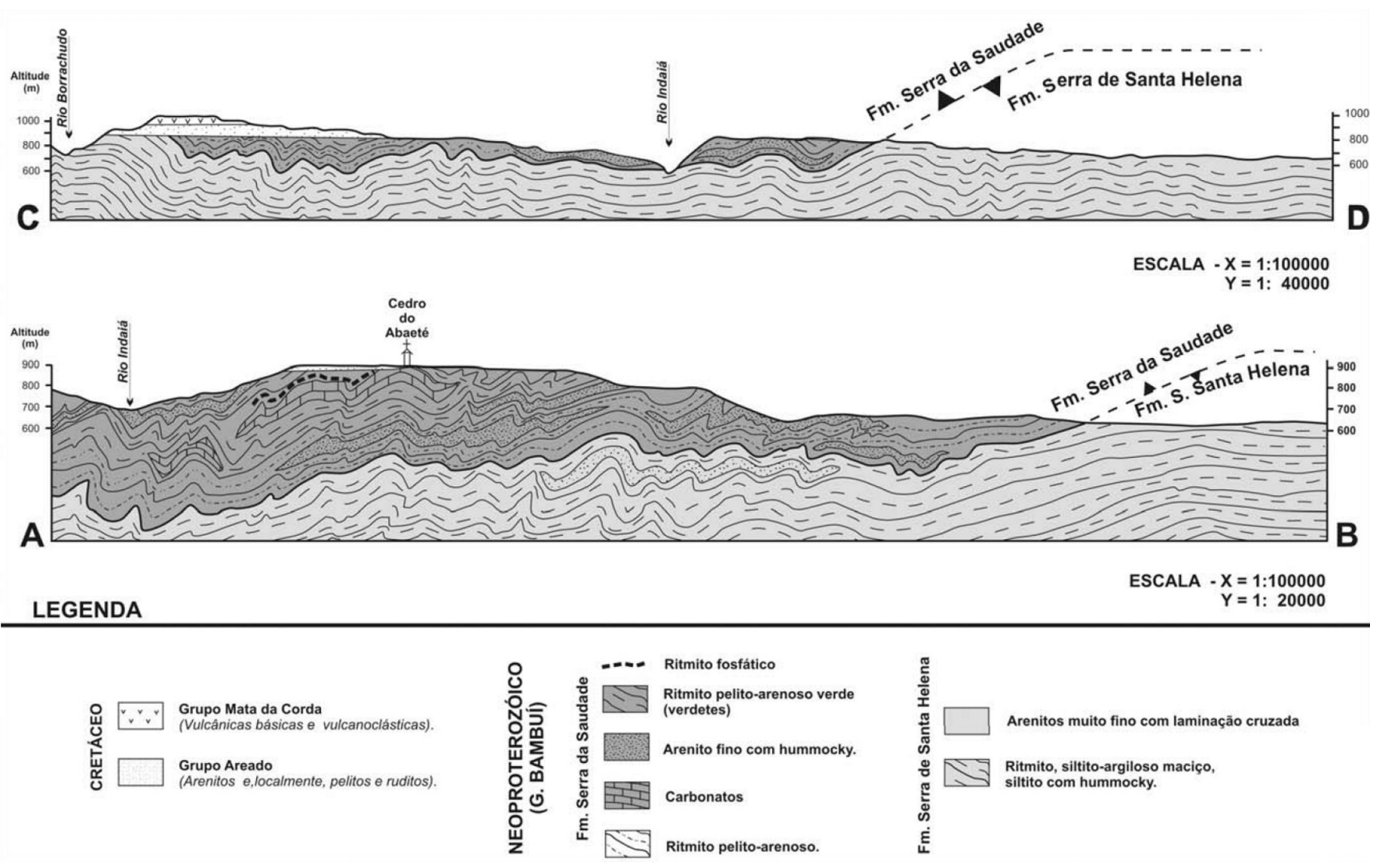

Figura 3 - Seções geológicas A-B e C-D transversais à Serra da Saudade. Exagero vertical é $5 X$ e 2,5 X respectivamente. Localização das seções está na figura 2. Modificado de Lima (2005).

apresentam teores de potássio $(\mathrm{K})$ de 7 a $14 \%$ e minerais como quartzo, K-feldspato, albita, mica branca, glauconita, clorita e opacos.

Análise difratométrica de raio-X (Tab. 1) e resultados de microanálise (Microssonda - JEOL Superprobe) a partir da amostragem dessas rochas indicam que o mineral responsável pela tonalidade verde é a glauconita. Os grãos de glauconita são geralmente inferiores a $3 \mu \mathrm{m}$, portanto na granulometria de argila. Entretanto, ocorrem grãos de glauconita de granulometria maior (silte-areia muito fina), dispersos nos leitos arenosos e indicando, nesse caso, uma origem detrítica.

A glauconita forma-se nas porções externas da plataforma, em zonas de baixo aporte sedimentar, afastada da foz dos rios. O material glauconítico se origina por halmirólise lenta dentro de um micro-ambiente redutor, em comunicação com águas oxigenadas (Odom 1984, Odin 1988, Guimarães 1997). O material glauconítico inicial é semelhante a um alumino-silicato férrico, sub-saturado em álcalis, semelhante a uma esmectita, com estrutura mal cristalizada (Guimarães 1997). Em condições de baixo aporte detrítico e suprimento constante de $\mathrm{Fe}$ e $\mathrm{K}$ pode evoluir para glauconita, no início da diagênese. Formadas na plataforma externa, elas podem ser retrabalhadas por ondas e correntes e, eventualmente preservadas, em condições alcalinas.

A interpretação de fácies de tempestitos para os ritmitos areno-pelíticos esverdeados, assim como a ocorrência de ciclos granodecrescentes ascendentes, a associação com arenitos com hummockys, sugerem processos de retrabalhamento em plataforma dominada por ondas de tempestades, intercalados com períodos de calmaria, que favoreceram a sedimentação das lâminas argilosas verdes, ricas em glauconita.

A relação estratigráfica entre as litofácies da Formação Serra da Saudade exibe um padrão granocrescente para o topo (coarsening upward), com ritmitos argilosos na base e arenitos no topo, indicando aumento na energia do ambiente deposicional, possivelmente de caráter regressivo. A sedimentação foi em contexto plataformal, abaixo do nível de ondas normais, com ação de ondas de tempestades, onde fluxos episódicos portadores de sedimentos se alternavam com deposição por decantação. As rocha terrígenas da Formação Serra da Saudade são imaturas, com deposição rápida, sedimentadas próximas à área fonte, em uma bacia sob influência de processos tectônicos colisionais (Guimarães 1997).

A litofácies de ritmito fosfático será descrita em separado, no próximo item, visando, também, uma discussão geral sobre o depósito de fosfato de Cedro do Abaeté.

Formação Três Marias A Formação Três Marias 


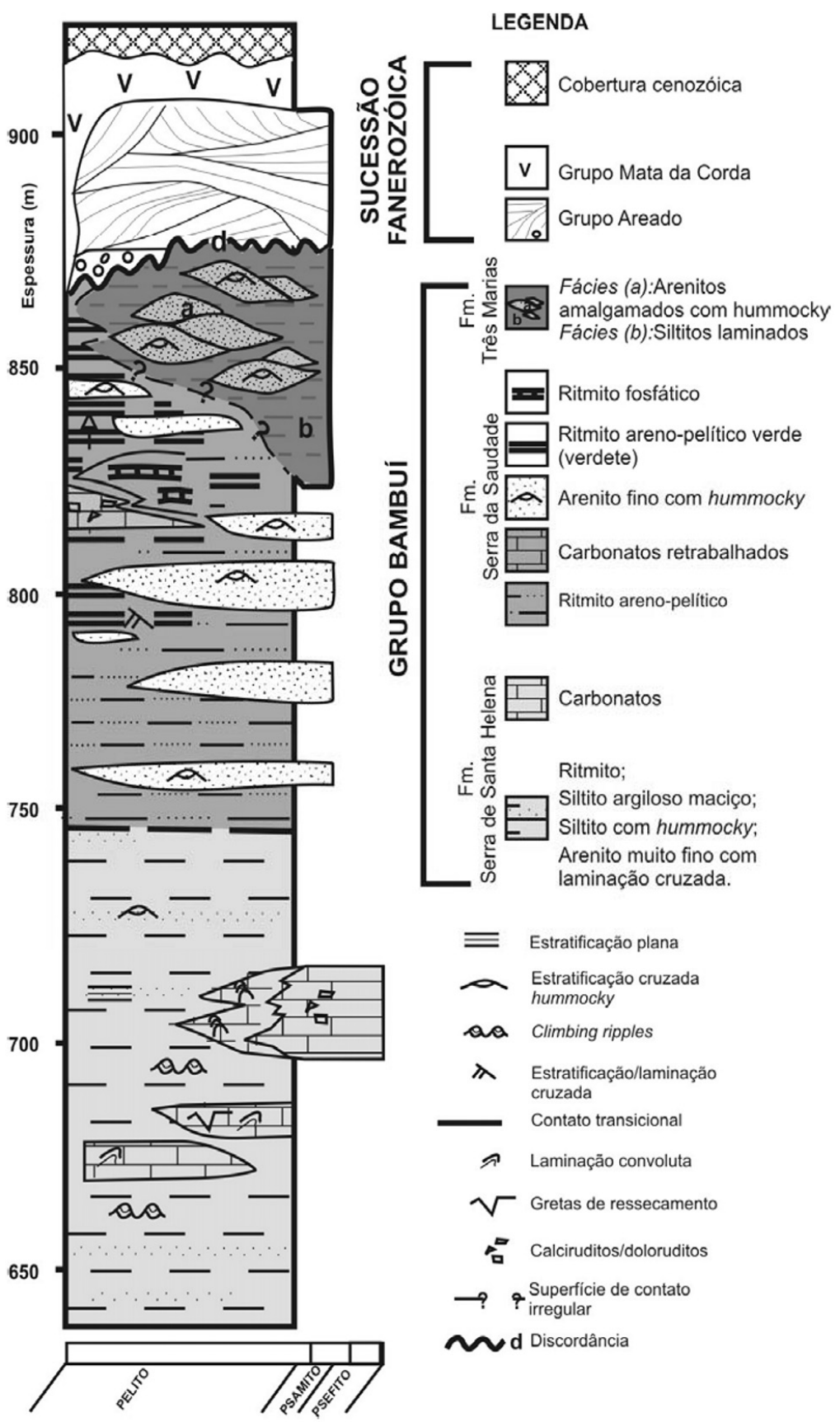

Figura 4 - Coluna estratigráfica do Grupo Bambuí na região da Serra da Saudade e adjacências. Escala vertical é aproximadamente 1:2 500. Segundo Lima (2005).

ocorre na parte norte da área investigada. A maior espessura identificada foi de cerca 80 metros, na extremidade norte da Serra do Palmital. Duas litofácies foram reconhecidas na Fm. Três Marias: (1) Arenitos amalgamados com hummocky; (2) Siltitos com laminação plana (Fig. 4). Os arenitos ocorrem em cristas acima de $750 \mathrm{~m}$ de altitude, são de granulometria média-fina, mostram disjunção esferoidal e estratificação hummocky. Os siltitos são de cor bege a rosada, geralmente alterados.

\section{GEOLOGIA DOS DEPÓSITOS FOSFÁTICOS DA}

SERRA DA SAUDADE O conhecimento sobre os depósitos fosfáticos da Serra da Saudade, remonta ao início da segunda metade do século XX. Couberam a Guimarães (1967) os primeiros estudos sobre a ocorrência, distribuição e mineralização dos chamados fosforitos do Abaeté. Ainda no final dos anos 60, ocorreu o Projeto Cedro do Abaeté (Chaves et al. 1971) para investigar, com maior detalhe, a mineralização e a viabilidade econômica dos fosforitos dos arredores da cidade de Cedro do Abaeté-MG. Os trabalhos de pesquisa fo- 
ram concentrados nas imediações das cidades de Cedro do Abaeté e Quartel São João. Ao final, constatou-se que as concentrações anômalas estavam relacionadas à siltitos e argilitos verdes do então Membro Serra da Saudade (Chaves et al. 1971).

Nas comunidades locais, a sabedoria popular acredita que a fertilidade natural das terras situadas à margem direita do Rio Indaiá, é proveniente da alta concentração de fosfato no solo. No entorno da cidade de Cedro do Abaeté existem lavras semi-artesanais da rocha fosfática e do verdete que, em conjunto, são triturados, pulverizados e ensacados para serem vendidos, sem nenhum tipo de beneficiamento, como fertilizantes.

Sedimentologia e petrografia do ritmito fosfático da Fm. Serra da Saudade A ocorrência desses depósitos está compreendida entre as cidades de Quartel São João e Cedro do Abaeté-MG. A espessura de toda essa unidade, baseada em furos de sondagem realizados por exploradores locais, nas proximidades de Cedro do Abaeté, não ultrapassa 20 metros. No entanto, é provável a existência de mais de um nível de ritmito fosfático, conforme informações de mineradores locais. Os corpos são estratiformes, descontínuos em mapa, concordantes com o acamamento dobrado, perfazendo lentes alongadas na direção norte-sul (Chaves et al. 1971). As camadas são deformadas por dobras angulares (tipo chevron), entretanto não apresentam xistosidade ou clivagem ardosiana.

A rocha mineralizada é representada, principalmente, por um ritmito areno-pelítico cinza claro, intercalado na seqüência de ritmitos areno-pelíticos verdes (verdetes), na forma de lentes estratiformes. Esses ritmitos fosfáticos ocorrem com diferentes graus de fraturamento, em função dos dobramentos de eixos N-S e com diferentes estágios de alteração intempérica.

Quando parcialmente alterada, essa rocha assume um aspecto bandado, devido a alternância de lâminas de diferentes colorações (Fig. 6). Os níveis claros, conforme difração de raio-X (Tab. 2) e resultados de microanálises, são ricos em caolinita e wavellita, $\left(\mathrm{Al}_{3}\left(\mathrm{PO}_{4}\right)_{2}(\mathrm{OH})_{3} .5 \mathrm{H}_{2} \mathrm{O}\right)$, ambos minerais supergênicos. A distribuição e a ocorrência de wavellita nessas rochas são muito irregulares e descontínuas, pois esse mineral ocorre principalmente como precipitado preenchendo fraturas preexistentes. Portanto, a concentração desse mineral também é função direta da intensidade de descontinuidades físicas presentes na rocha. Os níveis escuros são enriquecidos em manganês (Tab. 2), na forma de óxidos.

A tabela 2 apresenta os resultados referentes à constituição mineralógica e a dispersão dos minerais, em função da faixa granulométrica analisada, de amostras de ritmito fosfático extraído a $22 \mathrm{~m}$ de profundida$\mathrm{de}$, em furos de sondagens rasas, nos arredores de $\mathrm{Ce}$ dro do Abaeté-MG. De forma persistente, os minerais encontrados são: apatita e quartzo (dominantes); microclina, albita, wavellita e mica branca (intermediários); clorita e calcita (minoritários).

A análise mineralógica desses ritmitos fosfáti- cos mostrou que os grãos de apatita são, principalmente, de granulometria fina a muito fina, equivalente a areia muito fina/silte e argila, onde chegam a representar mais de $30 \%$ da composição mineralógica (Tab. 2). Por outro lado, minerais leves como quartzo, microclina e albita ocorrem principalmente nas granulometrias areia média e areia fina. Granulometrias maiores que areia fina mostram uma redução gradativa na participação de grãos de apatita na constituição mineral do ritmito fosfático. Dessa forma, coexistem, nessa litofácies, grãos detríticos maiores de minerais leves e grãos mais finos de minerais fosfáticos de maior densidade $\left(2,9 \mathrm{~g} / \mathrm{cm}^{3}\right)$. Esses minerais fosfáticos de grão fino representam uma matriz nas rochas detríticas mineralizadas (conforme o desenho esquemático da Fig. 7), pois em decorrência da diferença de densidade, o comportamento hidrodinâmico torna-se semelhante. Outros minerais pesados existentes são rutilo e zircão.

Por intermédio de microanálises, os grãos fosfáticos foram identificados como verdadeiras fluorapatitas (Fig. 8). Detalhes da morfoscopia dos grãos, obtidos por imagens de elétrons retroespalhados, indicam feições de retrabalhamento sedimentar. Identificou-se a presença de microfissuras, em grãos sub-arredondados a sub-angulosos, provavelmente associadas a impactos entre os grãos, durante o retrabalhamento sedimentar (Fig. 8).

Além dos grãos detríticos descritos, ocorre, também, material precipitado intersticial, o qual constitui um cimento diagenético de composição, freqüentemente, fosfática. Ao microscópio, esses diminutos grãos fosfáticos, na forma de colofana, dificilmente são individualizados. A colofana corresponde a uma massa agregada micro a criptocristalina, de cor amarelada a marrom, de finíssimos grãos de apatita e/ou fluorapatita

Mineral fosfático primário (francolita) não foi encontrado nas amostras estudadas. Entretanto, Chaves et al. (1971) descrevem algumas apatitas ricas em flúor e carbono que poderiam equivaler a verdadeiras francolitas - $\mathrm{Ca}_{5}\left(\mathrm{PO}_{4}, \mathrm{CO}_{3}, \mathrm{OH}\right)_{3}(\mathrm{~F}, \mathrm{OH})$.

Dessa forma, os teores de fosfato atribuídos a essa litofácies são dependentes das concentrações de apatita, fluorapatita e wavellita. A distribuição dos teores de $\mathrm{P}_{2} \mathrm{O}_{5}$ para esse depósito é hetereogênea e varia de 3 a $14 \%$ com valores médios em torno de $8 \%$ (Tab. 3). Em casos excepcionais, referentes a amostras muito intemperizadas e ricas em veios preenchidos por wavellita, os teores podem exceder a $25 \%$ de $\mathrm{P}_{2} \mathrm{O}_{5}$. Chaves et al. (1971) mostraram que partes das rochas enriquecidas por fosfato secundário estão associadas a zonas de charneira de anticlinais, orientados segundo N-S, pois nessas zonas as rochas apresentam uma maior intensidade de estruturas de deformação rúptil, o que facilitaria a remobilização e a precipitação desses fosfatos secundários.

Com base nesses dados pode-se afirmar que os ritmitos fosfáticos encontrados na Serra da Saudade nas cercanias de Cedro do Abaeté-MG, podem, apenas em parte, serem classificados como fosforitos, se tomarmos como critério para tal definição uma concentração míni- 


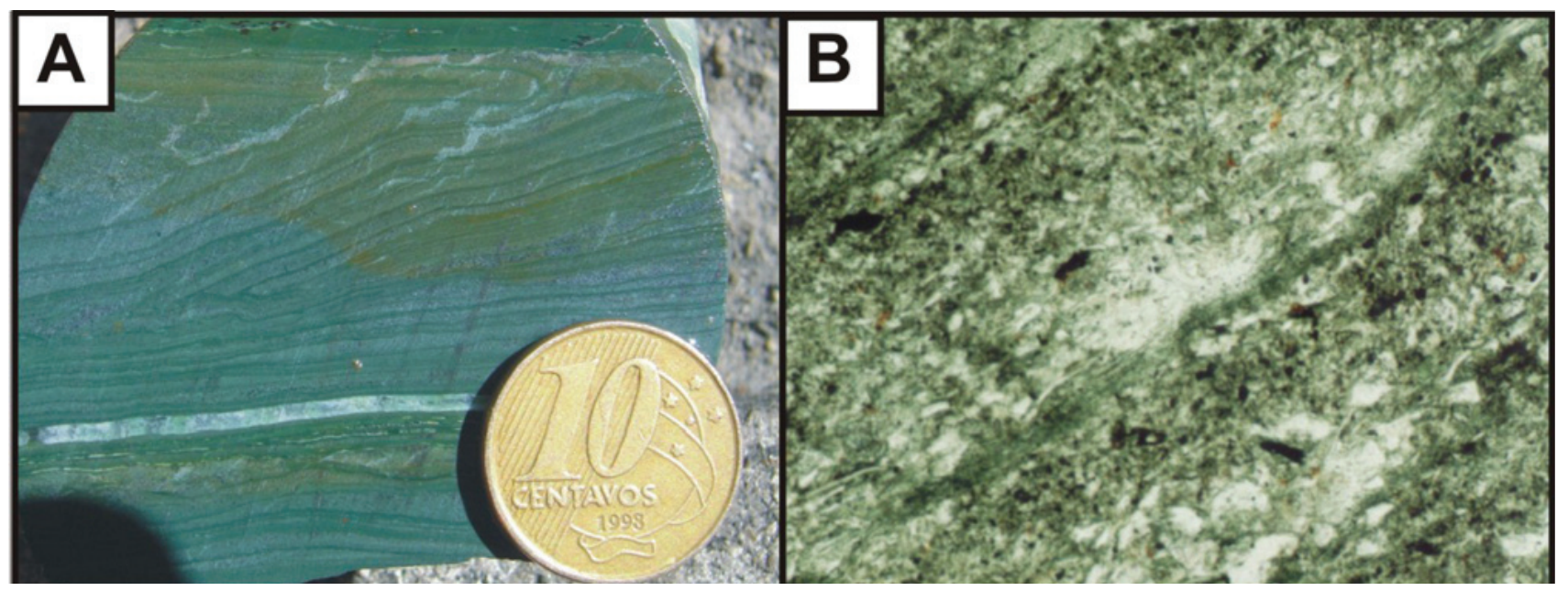

Figura 5 - (A) Ritmito areno-pelítico verde (verdete); (B) Fotomicrografia em luz analizada. Aumento 80 X, nicóis paralelos. Notar a presença de ciclos de granodecrescência ascendente. Cor verde das laminações argilosas é devido à presença de glauconita.

Tabela 1 - Análise mineralógica, por difração de raio-X, de uma amostra de ritmito pelitoarenoso verde. Análise efetuada no laboratório de identificação mineral do CDTN/CNEN.

\begin{tabular}{|c|c|c|c|c|c|}
\hline \multirow{2}{*}{$\begin{array}{l}\text { Fração granulo- } \\
\text { métrica }\end{array}$} & \multirow[b]{2}{*}{ Peso (\%) } & \multicolumn{4}{|c|}{ Mineral Identificado } \\
\hline & & $\begin{array}{c}\text { Predominante (> } \\
30 \%)\end{array}$ & $\begin{array}{l}\text { Maior } \\
(<30 \%)\end{array}$ & $\begin{array}{l}\text { Menor } \\
(<10 \%)\end{array}$ & Minoritário $(<3 \%)$ \\
\hline Areia grossa & 10,20 & Quartzo & $\begin{array}{l}\text { Mica branca } \\
\text { (Glauconita) }\end{array}$ & $\begin{array}{c}\text { Albita } \\
\text { Microclina }\end{array}$ & - \\
\hline Areia fina & 28,60 & Quartzo & $\begin{array}{l}\text { Mica branca } \\
\text { (Glauconita) }\end{array}$ & Albita Microclina & Clorita \\
\hline Silte & 19,60 & Quartzo & $\begin{array}{l}\text { Mica branca } \\
\text { (Glauconita) }\end{array}$ & Albita Microclina & Caolinita Clorita \\
\hline Argila & 41,60 & $\begin{array}{l}\text { Mica branca } \\
\text { (Glauconita) }\end{array}$ & Quartzo & Microclina & $\begin{array}{c}\text { Albita } \\
\text { Hematita } \\
\text { Caolinita } \\
\text { Clorita }\end{array}$ \\
\hline
\end{tabular}

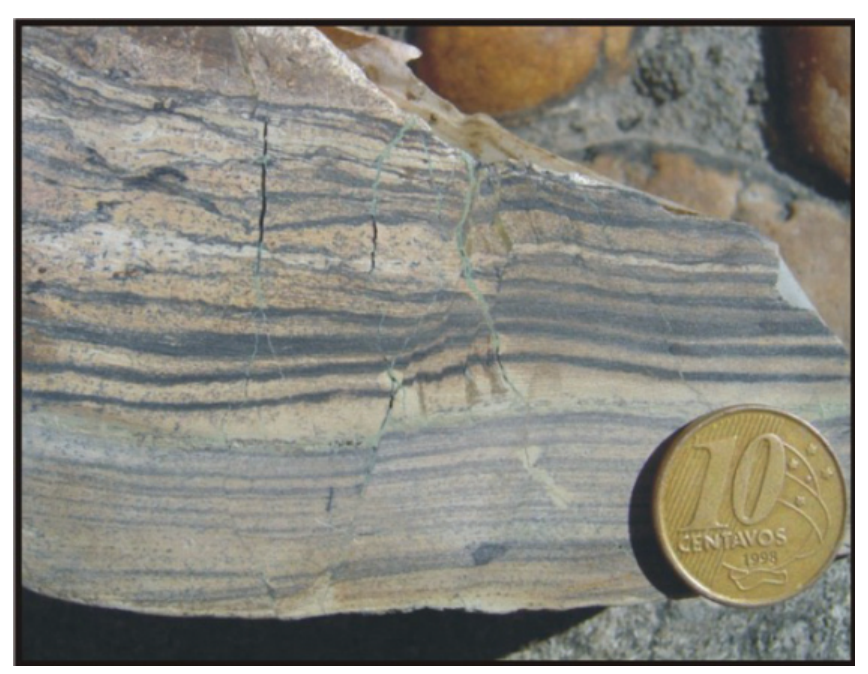

Figura 6 - Ritmito areno-pelitico fosfatizado, parcialmente alterado. Fosfatos sedimentares estão concentrados nos níveis mais claros. ma de $10 \%$ de $\mathrm{P}_{2} \mathrm{O}_{5}$ (Fölmi et al. 1991, Föllmi 1996).

DISCUSSÃO SOBRE A GÊNESE E A MINERALIZAÇÃO DO RITMITO FOSFÁTICO DA SERRA DA SAUDADE A partir das características estratigráficas, petrográficas e sedimentológicas apresentadas no item anterior, sobre os ritmitos fosfáticos da Fm. Serra da Saudade, pode-se inferir uma evolução geológica para o depósito mineral.

Mineral fosfático primário (francolita), apesar de não ter sido identificado neste trabalho, foi descrito por Chaves et al. (1971), na forma de carbo-apatitas, a partir de análise roentgenográfica (método relacionado à incidência e à difração de radiação eletromagnética sobre a rede cristalina de um mineral).

Minerais fosfáticos com forma detrítica identificados neste trabalho foram apatitas e fluorapatitas. Acredita-se que os minerais de fosfato precursores foram, originalmente, detríticos, pelas formas subarredondadas, granulometria fina, contraste de densidade 
Tabela 2 - Análise mineralógica, por difração de raio- $X$, do ritmito fosfático conforme faixas granulométricas especificas em mesh $-60+150$ (areia média a fina), $-50+325$ (areia muito fina a silte grosso), -325 (silte médio a argila). Minerais pesados foram separadas também de acordo com a susceptibilidade magnética em diferentes faixas de amperagem $(0,25 \mathrm{~A} ; 0,50 \mathrm{~A} ; 0,75 \mathrm{~A} ; 1,00 \mathrm{~A} ; 1,25 \mathrm{~A} ; 1,50 \mathrm{~A} ; 1,75 \mathrm{~A})$.

\begin{tabular}{|c|c|c|c|c|c|}
\hline \multirow{2}{*}{$\begin{array}{l}\text { Fração } \\
\text { (Malhas) }\end{array}$} & \multirow{2}{*}{$\begin{array}{c}\text { Peso } \\
(\%)\end{array}$} & \multicolumn{4}{|c|}{ Mineral Identificado } \\
\hline & & $\begin{array}{l}\text { Predominante } \\
\quad(>\mathbf{3 0} \%)\end{array}$ & $\begin{array}{c}\text { Maior } \\
(<\mathbf{3 0 \%})\end{array}$ & $\begin{array}{c}\text { Menor } \\
(<\mathbf{1 0} \%)\end{array}$ & $\begin{array}{c}\text { Minoritário } \\
(<\mathbf{3 \%})\end{array}$ \\
\hline $\begin{array}{l}\text { Leve } \\
(-60+150)\end{array}$ & 3,71 & Quartzo & $\begin{array}{l}\text { Apatita } \\
\text { Wavellita }\end{array}$ & Mica branca & Clorita \\
\hline $\begin{array}{l}\text { Inter } \\
(-60+150)\end{array}$ & 1,28 & Apatita & Quartzo & $\begin{array}{l}\text { Albita } \\
\text { Microclina } \\
\text { Wavellita }\end{array}$ & $\begin{array}{l}\text { Calcita } \\
\text { Mica branca }\end{array}$ \\
\hline$-150+325$ & 23,60 & Apatita & Quartzo & $\begin{array}{l}\text { Albita } \\
\text { Mica branca } \\
\text { Wavellita }\end{array}$ & $\begin{array}{l}\text { Calcita } \\
\text { Clorita } \\
\text { Microclina }\end{array}$ \\
\hline-325 & 64,82 & Apatita & Quartzo & Wavellita & $\begin{array}{l}\text { Albita } \\
\text { Calcita } \\
\text { Microclina } \\
\text { Microclina }\end{array}$ \\
\hline $\begin{array}{l}0,25 A \\
(-60+150)\end{array}$ & 0,16 & Apatita & Quartzo & - & $\begin{array}{l}\text { Mica branca } \\
\text { Wavellita }\end{array}$ \\
\hline $\begin{array}{l}0,50 A \\
(-60+150)\end{array}$ & 0,58 & Apatita & Quartzo & $\begin{array}{l}\text { Albita } \\
\text { Microclina }\end{array}$ & $\begin{array}{l}\text { Clorita } \\
\text { Wavellita }\end{array}$ \\
\hline $\begin{array}{l}0,75 A \\
(-60+150)\end{array}$ & 3,34 & Apatita & Quartzo & - & $\begin{array}{l}\text { Albita } \\
\text { Calcita } \\
\text { Microclina } \\
\text { Mica branca } \\
\text { Wavellita }\end{array}$ \\
\hline $\begin{array}{l}1,00 A \\
(-60+150)\end{array}$ & 1,82 & Apatita & Quartzo & - & $\begin{array}{l}\text { Albita } \\
\text { Calcita } \\
\text { Wavellita } \\
\end{array}$ \\
\hline $\begin{array}{l}1,25 A \\
(-60+150)\end{array}$ & 0,52 & Apatita & - & Quartzo & $\begin{array}{l}\text { Albita } \\
\text { Mica branca } \\
\text { Wavellita }\end{array}$ \\
\hline $\begin{array}{l}1,50 A \\
(-60+150)\end{array}$ & 0,12 & Apatita & - & Quartzo & $\begin{array}{l}\text { Mica branca } \\
\text { Wavellita }\end{array}$ \\
\hline $\begin{array}{l}1,75 \mathrm{~A} \\
(-60+150)\end{array}$ & 0.03 & Apatita & - & Quartzo & $\begin{array}{l}\text { Mica branca } \\
\text { Wavellita }\end{array}$ \\
\hline $\begin{array}{l}1,75 A \\
(-60+150)\end{array}$ & 0,02 & Apatita & - & Quartzo & Wavellita \\
\hline
\end{tabular}

em relação a grãos mais grossos de quartzo, pela grande participação de siliciclásticos e pela íntima associação com outras litofácies sedimentares, formadas a partir de depósitos detríticos retrabalhados. Entretanto, tanto as apatitas quanto as fluorapatitas são minerais autigênicos, possivelmente, gerados a partir da transformação de francolitas. Reações físico-químicas durante a diagênese, sob condições redutoras a sub-oxidantes, promoveram a abertura parcial da estrutura dos cristais de francolita e, provavelmente, a liberação de átomos de C, F e, até mesmo, Ca da rede cristalina (Dill 2001). Apesar de não serem de origem primária os grãos de apatita e fluorapatita são considerados, neste trabalho, como pseudomorfos de francolitas, pois preservaram a forma externa dos grãos primordiais, detríticos. Material precipitado interticial, representando cimento diagenético de composição fosfática foi, também, identifi- cado e significa a importância da diagênese na evolução da mineralização..

Os grãos fosfáticos de forma detrítica são principalmente de granulometria fina (areia muito fina/silte), portanto estando concentrados na matriz dos ritmitos areno-fosfáticos. Ao microscópio, esses diminutos grãos fosfáticos, na forma de colofana, dificilmente são individualizados. A colofana corresponde a uma massa agregada micro a criptocristalina, de cor amarelada a marrom, de finíssimos grãos de apatita e/ou fluorapatita.

Parte dos grãos de apatita e fluorapatitas exibem indicações de que foram retrabalhados. Dessa forma, uma gênese sinsedimentar para os precursores desses minerais é inferida. No entanto, o locus de formação do fosfato primário não deve ser coincidente com o sítio de deposição final dos ritmitos fosfáticos, uma vez que esses sedimentos são de natureza alóctone, como 

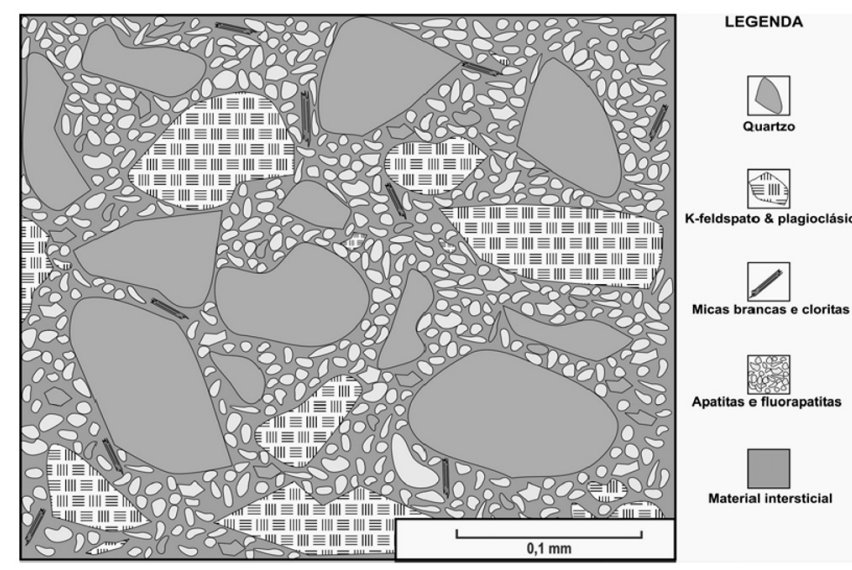

Figura 7 - Representação esquemática microscópica da distribuição dos minerais e de suas respectivas distribuições granulométrica no ritmito fosfático. Notar que as apatitas e florapatitas são encontradas como grãos mais finos, concentrados na matriz da rocha.. Segundo Lima (2005).

podemos perceber pelas inúmeras feições de retrabalhamento nesses depósitos. Dessa forma, a ocorrência de níveis de sedimentos enriquecidos em fosfatos detríticos se deve, principalmente, a processos físicos de concentração. Com base na proposta de classificação de fosforitos, conforme Follmi (1996), esses depósitos fosfáticos, ou parte deles, podem ser classificados como

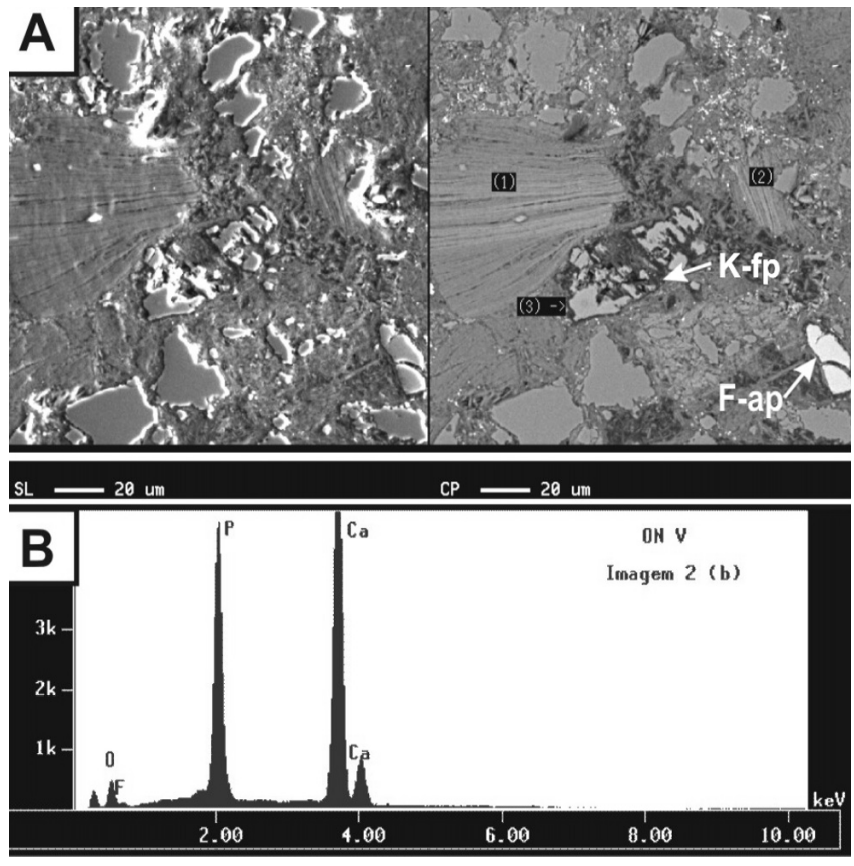

Figura 8 - (A) Imagem de elétrons retroespalhado, a partir da microssonda - JEOL Superprobe -, de ritmito fosfático, parcialmente, intemperizado. Em detalhe grãos de $K$-feldspato ( $K$-fp) e grão sub-arredondado de fluorapatita (F-ap); (B) Difratograma da fluorapatita selecionada em A. Segundo Lima (2005).

Tabela 3 - Análise Química Quantitativa por Espectrometria de Fluorescência de Raios-X, de algumas amostras de verdete e ritmito fosfático encontrados na Serra da Saudade. Laboratório de identificação mineral do CDTN/CNEN. Dados e localização das amostras em Lima (2005).

\begin{tabular}{|c|c|c|c|c|c|c|c|c|c|}
\hline \multirow{2}{*}{ Amostra } & \multicolumn{9}{|c|}{ Elemento Dosado (\%) } \\
\hline & $\mathrm{Al}_{2} \mathrm{O}_{3}$ & $\mathrm{CaO}$ & $\mathrm{Fe}_{2} \mathrm{O}_{3}$ & $\mathrm{~K}_{2} \mathrm{O}$ & $\mathrm{P}_{2} \mathrm{O}_{5}$ & $\mathrm{MnO}_{2}$ & $\mathrm{MgO}$ & $\mathrm{SiO}_{2}$ & $\mathrm{TiO}_{2}$ \\
\hline $\begin{array}{l}\text { Ponto }-98 \\
\text { (Verdete) }\end{array}$ & 15,3 & 0,01 & 6,06 & 10,6 & 2,26 & 0,78 & 1,60 & 64,3 & 0,86 \\
\hline $\begin{array}{l}\text { Ponto }-162 \mathrm{~A} \\
\text { (Ritmito fosfático - } 1^{\mathrm{a}} \\
\text { amostra) }\end{array}$ & 13,3 & 13,3 & 2,34 & 2,13 & 18,64 & 12,37 & 0,88 & 30,1 & 0,49 \\
\hline $\begin{array}{l}\text { Ponto }-162 \mathrm{~A} \\
\text { (Ritmito fosfático - } 2^{\mathrm{a}} \\
\text { amostra) }\end{array}$ & 15,1 & 0,10 & 5,61 & 7,97 & 10,62 & 2,48 & 1,26 & 50,3 & 0,79 \\
\hline $\begin{array}{l}\text { Ponto - 162B } \\
\text { (Verdete) }\end{array}$ & 15,5 & 0,03 & 5,94 & 11,9 & 2,34 & 0,27 & 1,58 & 62,8 & 0,80 \\
\hline $\begin{array}{l}\text { Ponto - } 37 \\
\text { (Verdete) }\end{array}$ & 13,9 & 0,02 & 8,26 & 11,6 & 1,86 & 0,46 & 1,57 & 58.2 & 0.80 \\
\hline $\begin{array}{l}\text { Ponto - } 37 \\
\text { (Verdete -Fração Argila) }\end{array}$ & 15,9 & 0,02 & 5,56 & 8,98 & 0,63 & 0,04 & 1,35 & 66,4 & 0,93 \\
\hline $\begin{array}{l}\text { Ponto - } 173 \\
\text { (Formação Serra da } \\
\text { Saudade) }\end{array}$ & 14,8 & 0,11 & 5,17 & 10,5 & 0,96 & 0,08 & 1,49 & 65,6 & 0,73 \\
\hline
\end{tabular}


fosforitos do tipo alóctone.

Além dos fosfatos detríticos autigênicos, existem fosfatos secundários, como a wavellita, formados a partir do intemperismo e encontrados, geralmente, como precipitados preenchendo fraturas e a porosidade secundária da rocha hospedeira. Altas concentrações de wavellita em parte das amostras de ritmitos fosfáticos se devem ao grau de alteração intempérica e à intensidade de fraturamento na rocha.

A gênese dos grãos primordiais de fosfato (francolita) é especulativa. Acredita-se que processos de ressurgência da água do mar (Follmi 1996), onde correntes mais densas, frias e saturadas em $\mathrm{P}_{2} \mathrm{O}_{5}$, ao chegarem às porções mais rasas, com baixo aporte sedimentar, favorecem a infiltração e o enriquecimento de águas conatas, responsáveis pela precipitação intersticial de francolita nos sedimentos (Föllmi 1996, Hiatt \& Budd 2001). Assim, acredita-se que o sítio de precipitação da francolita não coincida com o sítio deposicional dos ritmitos fosfáticos, que mostram várias feições de retrabalhamento e, portanto, são de natureza alóctone. A fonte do fosfato para as correntes de ressurgência é desconhecida, provavelmente atividade microbiana sin-sedimentar.

A evolução geológica da mineralização do ritmito fosfático pode ser sumarizada em quatro diferentes estágios ou fases (Tab. 4). A primeira fase (Fase 1) é representada pela precipitação do mineral fosfático primordial (francolita) em um ambiente deposicional de baixa energia e relativamente oxidante, condição necessária para a adsorção de moléculas de $\mathrm{P}_{2} \mathrm{O}_{5}$ por óxidos e hidróxidos.

A segunda fase (Fase 2) corresponde à geração dos depósitos alóctones do ritmito fosfático por meio da erosão e retrabalhamento do ambiente primário de precipitação da francolita, e transporte e acumulação dos grãos fosfáticos para o sítio de deposição final da litofácies de ritmito fosfático. Os agentes de erosão e transporte, nessa fase, estão relacionados a episódios de tempestades e a ação das ondas normais, provavelmente, intensificadas durante evento de recuo da linha de costa (evento regressivo). Dessa forma, tanto a primeira fase quanto a segunda fase são claramente singenéticas. A terceira fase (Fase 3) marca o surgimento dos minerais autigênicos apatita e fluorapatita, durante estágios de evolução diagenética, em condições redutoras a sub-oxidantes, a partir da alteração parcial de francolitas pré-existentes.

A fase final (Fase 4) é exclusivamente epigenética. Essa fase é caracterizada pela alteração supergênica dos minerais fosfáticos autigênicos pré-existentes e posterior geração de wavellita. Em razão das descontinuidades e da presença de níveis rochosos permeáveis, que facilitaram a percolação de soluções mineralizantes, os limites dessa mineralização secundária podem extrapolar os referenciais estratigráficos atribuídos aos ritmitos fosfáticos e afetar, até mesmo, outras litofácies.

CONCLUSÃO Na região da Serra da Saudade, a geologia regional é representada pelas unidades litoestratigráficas neoproterozóicas do Grupo Bambuí e pelas coberturas fanerozóicas. No Grupo Bambuí, doze litofácies foram identificadas sendo cinco referentes à Fm. Serra de Santa Helena, outras cinco à Fm. Serra da Saudade e duas à Fm. Três Marias.

A Formação Serra da Saudade é representada, em sua seção tipo, pelas litofácies de ritmito pelito-arenoso, arenito fino com hummocky, carbonatos retrabalhados, ritmito pelito-arenoso verde (verdete) e ritmito fosfático. Os ritmitos areno-pelíticos verdes (verdetes) são considerados fácies de tempestitos, e exibem ciclos de granodecrescência ascendente, com arenitos finos na base e sedimentos silto-argilosos no topo. Apresentam teores de potássio $(\mathrm{K})$ de 7 a $14 \%$; e minerais como quartzo, K-feldspato, albita, mica branca, glauconita, clorita e opacos. Glauconita é o mineral responsável pela cor verde dos verdetes. Os ritmitos fosfáticos correspondem a depósitos clásticos ricos em grãos fosfáticos de apatita, fluorapatita e, raramente, francolita, que exibem forma detrítica. Apatita e fluorapatita são minerais autigênicos gerados a partir da diagênese de prováveis francolitas (possível mineral fosfático primário). Evidências de retrabalhamento, a associação

Tabela 4 - Síntese sobre as quatro fases de mineralização dos depósitos fosfáticos da Serra da Saudade, na região de Cedro do Abaeté - MG. Segundo Lima (2005).

\begin{tabular}{c|l|l}
\hline Fase 1 & Geração de fostato primário & $\begin{array}{l}\text { Precipitação de francolita, segundo Chaves et al. (1971), em ambiente de baixa } \\
\text { energia e, preferencialmente, óxido. }\end{array}$ \\
\hline Fase 2 & $\begin{array}{l}\text { Formação de depósitos } \\
\text { alóctones de ritmito fosfático }\end{array}$ & $\begin{array}{l}\text { Erosão dos sítios de deposição primária, transporte, retrabalhamento e acumulação } \\
\text { dos grãos de francolita no sítio de deposição final de mais alta energia, por } \\
\text { processos físicos, principalmente, ondas e episódios de tempestades. }\end{array}$ \\
\hline Fase 3 & $\begin{array}{l}\text { Geração de fosfatos } \\
\text { autigênicos }\end{array}$ & $\begin{array}{l}\text { Transformação da francolita em pseudomorfos (apatita e fluorapatita) durante a } \\
\text { diagênese. }\end{array}$ \\
\hline Fase 4 & $\begin{array}{l}\text { Geração de fosfatos } \\
\text { supergênico }\end{array}$ & $\begin{array}{l}\text { Transformação dos minerais autigênicos em wavellita por processos de alteração } \\
\text { intempérica e concentração destes minerais em descontinuidades físicas das } \\
\text { rochas. }\end{array}$ \\
\hline
\end{tabular}


com fácies de tempestitos, a presença de partículas não fosfatizadas e de estruturas sedimentares, conduzem à classificação desses depósitos como fosforitos do tipo alóctone. Alguns leitos, mais intemperizados e fraturados, podem apresentar teores de $\mathrm{P}_{2} \mathrm{O}_{5}$ superiores a $25 \%$, devido, principalmente, as altas concentrações de wavellita, mineral secundário formado pela alteração supergênica dos minerais fosfáticos pré-existentes.

Agradecimentos Ao Instituto de Geociências da Universidade Federal de Minas Gerais, ao Programa de Pós-Graduação em Geologia do IGC-UFMG, ao Cen- tro de Desenvolvimento de Tecnologia Nuclear-CDTN, pela infra-estrutura colocada à disposição. A CAPES, pela bolsa de mestrado que permitiu a realização do trabalho. A FAPEMIG pelo projeto CRA-1321/98 que disponibilizou recursos para a realização da pesquisa. A CPRM-Serviço Geológico do Brasil, Grupo da Bacia do São Francisco, pelo acesso aos dados e discussões profícuas. A Comissão Organizadora do III Simpósio sobre o Cráton do São Francisco, em especial ao Dr. Aroldo Misi, e aos dois revisores da RBG, pela oportunidade de publicação.

\section{Referências}

Chaves A.G., Heineck C.A. \& Tavares W.P. 1971. Projeto Cedro do Abaeté. Belo Horizonte. Convênio DNPM/ CPRM 1971, 2v. (Rel. Final).

Chiavegatto J.R.S.1992. Análise estratigráfica das seqüências tempestíticas da Formação Três Marias (Proterozóico Superior), na porção meridional da Bacia do São Francisco. Dissertação de Mestrado, Departamento de Geologia, Escola de Minas, Universidade Federal de Ouro Preto, 216 p.

Costa M.T. da \& Branco 1961. Roteiro para a excursão Belo Horizonte - Brasília. In: SBG, Congresso Brasileiro de Geologia, 14, Belo Horizonte, EEUFMG-Instituto de Pesquisas Radioativas, Publicação 15, 25 p.

COMIG/CPRM. 2002. Projeto São Francisco. Módulo 1, Belo Horizonte, CD-Room

Dardenne M.A. 1978. Síntese sobre a estratigrafia do Grupo Bambuí no Brasil Central. In: SBG, Congresso Brasileiro de Geologia, 30, Recife, Anais, v. 2, p. 597-610.

Dardenne, M.A. 1981. Os Grupos Paranoá e Bambuí na Faixa Dobrada Brasília. In: SBG-Nucleo BA, Simpósio Cráton do São Francisco e Faixas Marginais, 1, Salvador, Anais, p. $140-157$.

Dardenne M.A., Trompette R., Magalhães L.F. \& Soares L.A. 1986. Proterozoic and Cambrian phosphorites regional review: Brazil. In: P.J. Cook \& J.H. Shergold (eds.) Phosphate deposits of the World. Proterozoic and Cambrian Phosphorites, Cambridge University Press, Cambridge, p. 116-131.

Dill H.G. 2001. The geology of aluminium phosphates and sulphates of the alunite group minerals: a review. EarthSci. Reviews, 53:35-93.

Föllmi K.B., Garvison R.N. \& Grimm K. 1991. Stratification in phosphatic sediments. In: G. Eisele, W. Ricken \& D. Seilacher (eds.) Cycles and Events in Stratigraphy, Springer, Heidelberg, p. 492-507.

Föllmi K.B. 1996. The phosphorus cycle, phosphogenesis and marine phosphate-rich deposits. Earth-Sci. Reviews, 40:55-124.

Guimarães D. 1967. Ocorrência de fosforita no município de Abaeté, Minas Gerais. DNPM-DGM. Notas Prelimina- res e estudos n.144, $18 \mathrm{p}$.

Guimarães E.M. 1997. Estudos de proveniência e diagênese com ênfase na caracterização dos filossilicatos dos Grupos Paranoá e Bambuí, na região de Bezerra-Cabeceiras $(G O)$. Tese de doutorado, Universidade de Brasília, $270 \mathrm{p}$.

Hiatt E.E. \& Budd D.A. 2001. Sedimentary phosphate formation in warm shallow waters: new insights into the paleooceanography of the Permian Phosphoria Sea from analysis of phosphate oxygen isotopes. Sed. Geol., 145:119-133.

Lima O.N.B. 2005. Grupo Bambuí: Estratigrafia regional no Alto Rio São Francisco e geologia dos depósitos fosfáticos da Serra da Saudade - MG. Dissertação de Mestrado, Instituto de Geociências, Universidade Federal de Minas Gerais, 142 p.

Lima S.A.A. 1997. Fácies, ambiente deposicional e aspectos diagenéticos das rochas carbonáticas da Formação Sete Lagoas na região norte de Minas Gerais, Bacia do São Francisco. Dissertação de Mestrado, Departamento de Geologia, Escola de Minas, Universidade Federal de Ouro Preto, $121 \mathrm{p}$.

Nobre-Lopes J. 1995. Faciologia e Gênese dos Carbonatos do Grupo Bambuí na região de Arcos, estado de Minas Gerais. Dissertação de Mestrado, Universidade de São Paulo, 166 p.

Odin G.S. (Ed.) 1988. Green marine clays. Developm. Sedimentol 45, Elsevier, Amsterdan, 445 p.

Odom I.E. 1984. Glauconite and celadonite minerals. In: S.W. Bailey (ed.) Micas. Mineralogical Soc. Amer., Reviews in Mineralogy, p. 545-572.

Uhlein A., Lima O.N.B.de, Fantinel L.M. \& Baptista M.C. 2004. Estratigrafia e evolução geológica do Grupo Bambuí, Minas Gerais. In: SBG, Congresso Brasileiro de Geologia, 42, Roteiro Geológico. Excursão 2, C-D Room, Araxá, 33 p.

Manuscrito CSF-03

Submetido em 22 de maio de 2006 Aceito em 30 de março de 2007 